\title{
A note on estimating market-based minimum capital risk requirements: a multivariate GARCH approach
}

Article

Accepted Version

Brooks, C., Clare, A.D. and Persand, G. (2002) A note on estimating market-based minimum capital risk requirements: a multivariate GARCH approach. The Manchester School, 70 (5). pp. 666-681. ISSN 1467-9957 doi:

https://doi.org/10.1111/1467-9957.00319 Available at https://centaur.reading.ac.uk/24153/

It is advisable to refer to the publisher's version if you intend to cite from the work. See Guidance on citing.

To link to this article DOI: http://dx.doi.org/10.1111/1467-9957.00319

Publisher: Blackwell

All outputs in CentAUR are protected by Intellectual Property Rights law, including copyright law. Copyright and IPR is retained by the creators or other copyright holders. Terms and conditions for use of this material are defined in the End User Agreement.

www.reading.ac.uk/centaur 
Central Archive at the University of Reading

Reading's research outputs online 
This is the authors' accepted manuscript of an article published in The Manchester School. The definitive version is available at www3.interscience.wiley.com 


\title{
Estimating market-based minimum capital risk requirements: A multivariate $\mathrm{GARCH}$ approach
}

by

\author{
C. Brooks, A. D. Clare and G. Persand ${ }^{1}$
}

\begin{abstract}
Internal Risk Management models of the kind popularised by J.P. Morgan are now used widely by the world's most sophisticated financial institutions as a means of measuring risk. Using the returns on three of LIFFE's most popular futures contracts, in this paper we investigate the possibility of using multivariate GARCH models for the calculation of Minimum Capital Risk Requirements (MCRRs). We propose a method for the estimation of the value at risk of a portfolio based on a multivariate GARCH model. We find that the consideration of the correlation between the contracts can lead to more accurate, and therefore more appropriate, MCRRs when compared with the values obtained from a univariate approach to the problem.
\end{abstract}

August 2001

Keywords: Minimum Capital Risk Requirements, Internal Risk Management Models, Multivariate GARCH Models.

JEL Classifications: C14, C15, G13

1 The authors affiliations are respectively: ISMA Centre, Dept of Economics, University of Reading, Whiteknights Park, PO Box 242, Reading, RG6 6BA. C.Brooks@ismacentre.reading.ac.uk; Monetary Instruments and Markets, Bank of England, Threadneedle Street, London, EC2R 8AH; and ISMA Centre, Dept of Economics, University of Reading, Whiteknights Park, PO Box 242, Reading, RG6 6BA. g.persand@ismacentre.reading.ac.uk. The authors are grateful to an anonymous referee for useful comments on a previous version of this paper. The usual, disclaimer applies. We would also like to point out that the views expressed in this paper do not necessarily represent those of the Bank of England. 


\section{Introduction}

Following the Second Capital Adequacy Directive (known as CAD II), European investment firms and banks are now permitted to determine their own levels of capital to cover position risk using internal risk management models (IRMMs). Financial institutions from other regulatory jurisdictions have been using these models for some time. The models generally involve the assessment of an institution's value at risk (VaR), inherent in its trading book. For each position, the $\mathrm{VaR}$ is an estimate of the probability of likely losses which might occur from changes in market prices; the MCRR is defined as the minimum amount of capital required to absorb all but a pre-specified percentage of these possible losses (usually $5 \%$ or 1\%). These models are permitted as long as they have been adequately back and stress tested. It is likely that the value at risk approach will become even more widely adopted over time, since it is thought that such models lead to a reduction in capital charges (see Clifford Chance (1998)). It is thus essential that the various techniques which are available for calculating capital risk requirements are subjected to a complete evaluation and comparison. Here we explore the possibility of using multivariate GARCH models to calculate MCRRs.

We extend recent research in this area (see, for example, Hsieh, 1993), to calculate capital risk requirements for three popular financial futures contracts traded on the London International Financial Futures Exchange (LIFFE) using multivariate GARCH models (MGARCH). These models are designed to capture volatility linkages and spillovers between markets, which could be important if the volatilities move together over time. In its pioneering VaR software, RiskMetrics $^{\mathrm{TM}}$, J.P. Morgan calculates correlations based upon equally and exponentially weighted moving averages (see Brooks and Persand, 2000 for a discussion of this and alternative methodologies). Recent research by Engle and Manganelli (1999) has also considered the question of whether aggregated multivariate risk measures are superior to 
univariate measures defined directly on the portfolio ${ }^{1}$.

The remainder of this paper is organised as follows. In Section 2, we describe the data employed in this study and outline the econometric procedure, which we use to estimate the models. In Section 3, we present the various methodologies used to determine the appropriate capital risk requirements, while the associated results which are generated are described in Section 4. Section 5 discusses the use of our approach for assessment of value at risk for portfolios and finally, Section 6 concludes the paper with suggestions for future research in this area.

\section{Data and GARCH modelling}

\subsection{Data}

We calculate MCRRs for three LIFFE futures contracts - the FTSE-100 Index Futures Contract, the Long Gilt Futures Contract and the Short Sterling Interest Rate Futures Contract - based upon their daily settlement prices $^{2}$. We thus investigate the possibility of taking a combined approach to the calculation of MCRRs for a netted portfolio of equity, cash, and bonds. The data was collected from Datastream International, and spans the period $24^{\text {th }}$ May 1991 to $16^{\text {th }}$ September 1996. We have chosen this sample length in order to make meaningful comparisons with the results of Hsieh (1993), who uses a similar sample size in calculating MCRRs based upon univariate models for a number of US derivatives contracts. The sample period includes sterling's exit from the European Exchange Rate Mechanism in September 1992. Observations corresponding to UK public holidays (i.e., when LIFFE was

\footnotetext{
${ }^{1}$ See also Engle (2000) and Berkowitz (2000) on the issue of univariate versus multivariate models.

${ }^{2}$ Because these contracts expire four times per year - March, June, September and December - to obtain a continuous time series, we use the closest to maturity contract unless the next closest has greater volume, in which case we switch to this contract.
} 
closed) were deleted from the data set to avoid the incorporation of spurious zero returns, leaving 1344 trading days in the sample. In the empirical work below, we use the daily log return of the original price series. Table 1 presents the summary statistics for the three series. All three security returns series show strong evidence of leptokurtosis. They are also highly skewed - the FTSE-100 and Short Sterling contract returns are skewed to the right while the returns on the Long Gilt contract are skewed to the left. The Bera-Jarque test statistic consequently rejects normality for all three derivative return series. Table 1 also includes the autocorrelation functions at lags 1 to 5 for each of the component return series and for the portfolio, together with the Ljung-Box joint statistic for testing the null hypothesis that all of the first ten lags are not related to the current value of the return. The statistics in Table 1 clearly show that none of the returns series are linearly related to their previous values, and in fact, only the short sterling has a significant autocorrelation coefficient at lag 3 .

Figures 1 to 3 plot the FTSE, Long Gilt and Short Sterling index returns respectively over the sample period. The FTSE returns are clearly the most volatile, while Short Sterling movements are almost always small except for a small number of very large outlying observations associated with the ERM Sterling crisis.

\subsection{GARCH modelling}

We use a Multivariate GARCH $(1,1)(\mathrm{MGARCH})$ model for the determination of values at risk. These models are now widely used in the finance literature. ${ }^{3}$ For the purposes of comparison, we also calculate MCRRs based upon a univariate $\operatorname{GARCH}(1,1)$ model for an equally weighted portfolio of the returns on the three LIFFE contracts.

\footnotetext{
${ }^{3}$ See for example, Bollerslev et al. (1988), Schwert and Seguin (1990), Bollerslev (1990), or Ng (1991).
} 
It is clearly an empirical question as to whether a multivariate approach, or a univariate approach applied directly to the portfolio is preferable. It is intuitive to expect that the univariate approach would dominate, since in this case the final object of interest (the portfolio return) is modelled directly. Such an approach also does not encounter difficulties with an assumed form for the relationships between the series in the portfolio, as the multivariate approach would. The estimation of multivariate models can quickly become infeasible as the number of assets in the portfolio is increased. On the other hand, the multivariate approach has several advantages. First, under a multivariate approach, if the weights of the assets in the portfolio change, the model does not have to be re-estimated. Second, and more importantly, estimating multivariate models provides the user with useful additional information concerning the relationships between the series and permits the easy use of scenario analysis.

In a univariate context, the $\operatorname{GARCH}(1,1)$ model has been found to describe adequately the conditional second moments of the futures contract returns which we employ in this study (see Brooks et al., 2000). The univariate $\operatorname{GARCH}(1,1)$ model which we estimate is written as:

$$
\begin{aligned}
& x_{t}=\mu+h_{t}^{1 / 2} \omega_{t} \\
& h_{t}=\gamma+\alpha \varepsilon_{t-1}^{2}+\beta h_{t-1}
\end{aligned}
$$

where: $x_{t}=\log \left(P_{t} / P_{t-1}\right)$ and where $P_{t}$ is the price of the portfolio; $\omega_{t}=\hat{\varepsilon}_{t} / \hat{h}_{t}^{1 / 2}, \omega_{t} \sim N(0,1)$; and where, $\mu, \gamma, \alpha$ and $\beta$ are coefficients to be estimated. In Table 2 we present estimates of expression (1) for this futures contract portfolio. The key parameters of this model are all significant at the $99 \%$ level of confidence or higher. Hence, if current regulations would allow firms to treat their book as a portfolio rather than comprising of individual positions, one could conceivably use the model in Table 2 as the basis for VaR-type calculations (as we 
do below). However, the implicit assumption which one would be making if one were to calculate separate MCRRs for the individual contracts based upon a univariate model of the kind given in expression (1) is that the correlations between the contracts are zero. However, the underlying markets, and hence these contracts, may well be affected by common factors; it is not unreasonable then to expect them to be related. An alternative to the univariate, portfolio approach represented in expression 1 and in Table 2 is to use an MGARCH model. The unconditional correlations are presented in Table 3, are reasonably high, suggesting that any movement in one of the financial contracts will on average be closely related to movements in the other two. Although a finding of large unconditional correlations does not imply conditional correlation, the use of a multivariate GARCH system to model the comovement between the three contracts, and to capture the conditional heteroscedasticity in the data, would seem appropriate. Here we use a $\operatorname{MGARCH}(1,1)$ model with time-varying conditional covariances and correlations. The conditional mean equations are given as:

$$
\begin{aligned}
& x_{1 t}=\lambda_{(1) 0}+h_{11 t}^{1 / 2} \omega_{1 t}, \omega_{1 t}=\hat{\varepsilon}_{1 t} / \hat{h}_{11 t}^{1 / 2} \text { and } \omega_{1 t} \sim N(0,1) \\
& x_{2 t}=\lambda_{(2) 0}+h_{22 t}^{1 / 2} \omega_{2 t}, \omega_{2 t}=\hat{\varepsilon}_{2 t} / \hat{h}_{22 t}^{1 / 2} \text { and } \omega_{2 t} \sim N(0,1) \\
& x_{3 t}=\lambda_{(3) 0}+h_{33 t}^{1 / 2} \omega_{3 t}, \omega_{3 t}=\hat{\varepsilon}_{3 t} / \hat{h}_{33 t}^{1 / 2} \text { and } \omega_{3 t} \sim N(0,1)
\end{aligned}
$$

where: $x_{1 t}, x_{2 t}$ and $x_{3 t}$ are the log price changes for the FTSE-100 Index, Long Gilt and Short Sterling contracts respectively. The conditional variance equations are given as:

$$
\begin{aligned}
& h_{11 t}=\alpha_{(1) 0}+\alpha_{(1) l} \varepsilon_{1 t-1}^{2}+\beta_{(1) l} h_{11 t-1} \\
& h_{22 t}=\alpha_{(2) 0}+\alpha_{(2) l} \varepsilon_{2 t-1}^{2}+\beta_{(2) l} h_{22 t-1} \\
& h_{33 t}=\alpha_{(3) 0}+\alpha_{(3) l} \varepsilon_{3 t-1}^{2}+\beta_{(3) l} h_{33 t-1}
\end{aligned}
$$

while the conditional covariance equations are given as:

$$
h_{12 t}=\gamma_{(12) 0}+\gamma_{(12) l} \sqrt{h_{11 t-1}} \cdot \sqrt{h_{22 t-1}}+\gamma_{(12) 2} h_{12 t-1}
$$




$$
\begin{aligned}
& h_{13 t}=\gamma_{(13) 0}+\gamma_{(13) 1} \sqrt{h_{11 t-1}} \cdot \sqrt{h_{33 t-1}}+\gamma_{(13) 2} h_{13 t-1} \\
& h_{23 t}=\gamma_{(23) 0}+\gamma_{(23) 1} \sqrt{h_{22 t-1}} \cdot \sqrt{h_{33 t-1}}+\gamma_{(23) 2} h_{23 t-1}
\end{aligned}
$$

where, $h_{12 t}$ is the conditional covariance between the FTSE-100 Index and the Long Gilt contract, $h_{13 t}$ is the conditional covariance between the FTSE-100 Index and the Short Sterling contract and $h_{23 t}$ is the conditional covariance between the Long Gilt and Short Sterling contract, and where the $\gamma$ coefficients remain to be estimated. The time-varying conditional covariances are proportional to the square root of the product of the corresponding two one-period lagged conditional variances, together with the previous day's conditional covariances. Under the assumption of conditional normality, the parameters in the conditional mean and variance equations can be estimated by maximising the log likelihood function:

$$
\ell(\theta)=-\frac{T N}{2} \log 2 \pi-\frac{1}{2} \sum_{t=1}^{T}\left(\log \left|h_{t}\right|+\varepsilon_{t}^{\prime} h_{t}^{-1} \varepsilon_{t}\right)
$$

where, $N$ is the number of assets and $T$ is the number of observations. $\theta$ denotes all the unknown parameters in $x_{t}$ and $h_{t}$.

The results from estimating the multivariate model are presented in Table 4. The persistence in shocks to volatility implied by the parameter estimates (i.e. the sum of $\alpha_{1}$ and $\beta_{1}$ ) are very high. The implication is that large innovations cause volatility to remain high for a protracted period, and consequently that the amount of capital required to cover this period of high volatility is also high. For the estimated multivariate GARCH models, there is also strong evidence of linkages, or volatility spillovers, between the three series. The coefficient for the link between the FTSE-100 and Long Gilt contracts, and between the FTSE-100 and ShortSterling contracts are significant, although those between the Short Sterling and Long Gilt contracts are not. For information, in Figure 4 we present $h_{12}$, the estimated daily conditional 
covariance between the FTSE-100 and Long gilt contracts, which demonstrates the timevarying nature of the relationship between the two contracts. The estimated covariance is highly variable; for example, it trebles at the end of 1992 before falling back to its previous level at the start of 1993.

\section{A methodology for estimating MCRRs}

\subsection{Calculating MCRRs}

We can use the models presented in Tables 2 and 4 to calculate minimum capital risk requirements for 1 day, 1 week, 1 month and 3 month investment horizons by simulating the conditional densities of price changes, using Efron's (1982) bootstrapping methodology. The $\omega_{t} s$ (that is the $\omega, \omega_{1}, \omega_{2}$ and $\omega_{3}$ coefficients from expressions (1) and (2) to (4)) are drawn randomly with replacement from the standardised residuals of the univariate model shown in expression (1) for the futures contract portfolio and from the multivariate model given in expressions (2) to (10). This enables us to generate a path of future $x_{t}$ 's, using the estimates of $\alpha, \beta, \gamma$ and $\lambda$ giving multi-step ahead forecasts of the $h_{t}$ 's.

To calculate the appropriate capital risk requirement from this bootstrapping procedure, we need to estimate the maximum loss that the position might experience over the proposed holding period ${ }^{4}$. For example, by tracking the daily value of a long futures position (or a long position in the portfolio) and recording its lowest value over the sample period, we can report the maximum loss per contract for this particular simulated path of futures prices. Repeating this procedure for 20,000 simulated paths generates an empirical distribution of the maximum loss. This maximum loss $(Q)$ is given by:

\footnotetext{
${ }^{4}$ The current BIS rules state that the MCRR should be the higher of the (i) average MCRR over the previous 60 days or (ii) the previous trading days' MCRR, multiplied by a factor of 3. In this paper, we do not use the scaling
} 


$$
Q=\left(x_{0}-x_{1}\right) \times \text { Contracts }
$$

where $x_{0}$ is the price at which the contract is initially bought or sold; and $x_{1}$ is the lowest simulated price for a long position, or the highest simulated price for a short position over the holding period. Assuming (without loss of generality) that the number of contracts held is 1 , we can write the following:

$$
\frac{Q}{x_{0}}=\left(1-\frac{x_{1}}{x_{0}}\right)
$$

In this case, since $x_{0}$ is a constant, the distribution of $Q$ will depend on the distribution of $x_{1}$. In his work, Hsieh (1993) assumed that prices are lognormally distributed, i.e. that the log of the ratios of the prices, $\operatorname{Ln}\left(x_{1} / x_{0}\right)$, are normally distributed. However, in this paper, we do not impose this restriction, but instead $\operatorname{Ln}\left(x_{1} / x_{0}\right)$ is transformed into a standard normal distribution by matching the moments of $\operatorname{Ln}\left(x_{1} / x_{0}\right)$ ' s distribution to one of a set of possible distributions known as the Johnson (1949) distribution. Matching moments to the family of Johnson distributions (Normal, Lognormal, Bounded and Unbounded) requires a specification of the transformation from the $\operatorname{Ln}\left(x_{1} / x_{0}\right)$ distribution to a standard normal distribution. In this case, matching moments means finding a distribution, whose first four moments are known, i.e. one that has the same mean, standard deviation, skewness and kurtosis as the $\operatorname{Ln}\left(x_{1} / x_{0}\right)$ distribution. For all three contracts, the $\operatorname{Ln}\left(x_{1} / x_{0}\right)$ distributions were found to match the Unbounded distribution. The $5^{\text {th }}$ percentile of $\operatorname{Ln}\left(x_{1} / x_{0}\right)$ is given by:

$$
\frac{\operatorname{Ln}\left(\frac{x_{1}}{x_{0}}\right)-m}{S d}= \pm \alpha
$$

factor. 
where $\alpha$ is the $5^{\text {th }}$ percentile from the Johnson Distribution, $m$ is the mean of $\operatorname{Ln}\left(x_{1} / x_{0}\right)$ and $S d$ is the Standard Deviation of $\operatorname{Ln}\left(x_{1} / x_{0}\right)$. Cross-multiplying and taking the exponential, and using expression (13), we can write:

$$
\frac{Q}{x_{0}}=1-\text { Exponential }[( \pm \alpha \times S d)+m]
$$

With this expression we can calculate the expected loss as a proportion of the initial value of the position. We estimate confidence intervals for these MCRRs by using the jackknife-afterbootstrap methodology to construct the standard error of $\operatorname{Ln}\left(x_{1} / x_{0}\right)$ see Efron and Tibshirani (1993)). These confidence intervals are estimated to give an idea of the likely sampling variation in the MCRR point estimates and help determine whether the differences in the MCRRs for the various models are significantly different. The confidence interval of $\left(\frac{Q}{x_{0}}\right)_{(5 \%)}$ is then given by

$$
1-\operatorname{Exp}\left\{\operatorname{Ln}\left(\frac{x_{1}}{x_{0}}\right)_{(5 \%)} \pm \alpha * S E\left[\operatorname{Ln}\left(\frac{x_{1}}{x_{0}}\right)_{(5 \%)}\right]\right\}
$$

The jackknife-after-bootstrap provides a method of estimating the standard error of the $5^{\text {th }}$ percentile of $\operatorname{Ln}\left(x_{1} / x_{0}\right)$ using only information in the 20,000 bootstrap samples.

\subsection{Testing the accuracy of the MCRRs}

To verify the accuracy of this methodology, we compared the actual daily profits and losses incurred by holding an equal amount of each futures security using either the daily MCRR forecast based upon the portfolio of securities, or upon the equally weighted MCRRs from the multivariate daily MCRR forecasts. Our measure of model performance is a count of the number of times the MCRR forecast "underpredicts" losses in both an in-sample test of the last trading year, and an out-of-sample test (a "back test" in the terminology of the Basle 
Committee) period for the 250 trading days. Such tests represent the preferred method by which the Basle Committee believes VaR models should be assessed. The nominal probability that the observed loss exceeds the MCRR forecasts is by definition 5\%, and hence if the observed loss exceeds the MCRR more than 5\% of the time, we can reject the underlying model on the grounds that the capital charge would be too low to cover $95 \%$ of foreseeable losses. On the other hand, a model which generates a proportion of exceedences considerably below $5 \%$ should also be rejected on the grounds that too high a capital charge would have been applied. We also construct a likelihood ratio test for the proportion of failures that tests the null hypothesis that the actual and nominal coverage rates are unconditionally equal. The probability of observing $x$ failures in an actual sample of independent observations of size $K$ will be distributed binomially, leading to the following test statistic distributed $\chi^{2}(1)$ under the null

$$
U C F\left(K, x, p^{*}\right)=-2 \log \left[\left(1-p^{*}\right)^{K-x}\left(p^{*}\right)^{x}\right]+2 \log \left[\left(1-\left(\frac{x}{K}\right)\right)^{K-x}\left(\frac{x}{K}\right)^{x}\right]
$$

where $p^{*}$ is the nominal probability of exceedence under the null hypothesis $(0.05)$.

Christoffersen (1998) and Diebold and Christoffersen (2000) argue that it is important to examine the conditional coverage of a value at risk model as well as its unconditional coverage. A model with correct conditional coverage would have a proportion of exceedences that was not statistically significantly different from the nominal proportion of exceedences, together with a time series of exceedences that was iid. In other words, correct conditional coverage implies correct unconditional coverage plus independent exceedences. Tests for independence in the exceedences can be conducted in a number of ways, but an obvious approach is to take the time series of exceedences (i.e. the series of 0 's and 1's, where $0=$ no exceedence at that point in time and 1 implies a violation at that point in time). This indicator 
variable is then regressed on a constant and the past conditional variances for the model. Correct conditional coverage should imply that the intercept is not significantly different from 0.05 , and the slope coefficient should be not significantly different from zero. Terming the intercept parameter in such a regression $\mu$, and the slope parameter $\lambda$, the hypotheses are respectively $\mathrm{H}_{0}: \mu=0.05$ and $\mathrm{H}_{0}: \lambda=0$.

\section{Results}

We calculate the Minimum Capital Risk Requirement using the semi-parametric approach outlined in Section 3 based upon the bootstrap, for 1 day, 1 week, 1 month and 3 month investment horizons. We begin by using the equally-weighted return on the portfolio of long futures contract positions, where the portfolio consists of the three LIFFE futures contracts. The MCRR is then determined by using the resulting series as if it were a set of returns on an individual asset. In this fashion, the correlations between contract returns are automatically accounted for in the return calculation. We shall refer to this method as the 'full valuation approach' since the full value of the portfolio is determined at each point in time. Risk managers have a statutory requirement to monitor the correlations between security returns which comprise their portfolios, but this information is not used in the full valuation method. However, we present results relating to this portfolio to serve as a benchmark, by which we can gauge the performance of the MCRRs based upon the MGARCH model.

With these drawbacks relating to the full valuation approach in mind, the MGARCH approach which models both volatilities and correlations would appear to be better suited to the calculation of MCRRs in a portfolio context. Using the MGARCH model we calculate MCRRs for each security and aggregate these to a portfolio MCRR using the JP Morgan RiskMetrics $^{\mathrm{TM}}$ approach. For an equally weighted, three-asset portfolio we can write: 


$$
M C R R_{P}=\sqrt{\begin{array}{l}
a^{2} M C R R_{A}^{2}+b^{2} M C R R_{B}^{2}+c^{2} M C R R_{C}^{2} \\
+2 a b \rho_{A B} M C R R_{A} M C R R_{B} \\
+2 a c \rho_{A C} M C R R_{A} M C R R_{C} \\
+2 b c \rho_{B C} M C R R_{B} M C R R_{C}
\end{array}}
$$

where $A, B$, and $C$ denote the FTSE, Long Gilt and Short Sterling contracts respectively; $a=b=c=1 / 3$; and where $\rho_{\mathrm{AB}}, \rho_{\mathrm{AC}}$ and $\rho_{\mathrm{BC}}$ are the correlations derived from the conditional covariance equations from the MGARCH model.

The MCRRs and their respective 95\% confidence intervals are presented in Panels A and B of Table 5. The table entries are averages, and each MCRR is calculated using a window of length 1344, rolled through the sample one observation at a time and computing the value at risk for the required horizon. It can be seen that MCRRs calculated using the portfolio of returns, which endogenises the estimation of the correlations, are considerably larger than those based on the MGARCH model. For example, for a one-month investment horizon, for a long position, the MCRR based on the portfolio of returns is $14.13 \%$, but only $11.91 \%$ based on the MGARCH model. The difference between the two approaches is further emphasised by the fact that the confidence intervals for the two methods never overlap. This indicates that there is a statistically significant difference between the estimated VaRs under the two methodologies.

Tests of model adequacy are presented in Panels C and D of Table 5. The results show the percentage of violations of the nominal VaR over in-sample and out-of-sample periods for 250 days (the horizon required by the Basle Committee rules). We can now see that the multivariate approach appears to be generally more accurate than the full valuation method, since in the case of both long and short positions, the percentage of violations is usually closer 
to the chosen value of 5\%. For example, with regard to the in-sample test for short positions, losses were incurred $3.4 \%$ of the time with the full valuation method, but $4.8 \%$ of the time using the MGARCH model. For the out-of sample test, the full valuation approach leads to uncovered losses for $4.0 \%$ of the time, but for $4.8 \%$ of the time using the MGARCH model. These violations compare favourably with those presented in Brooks et al (2000), who estimate separate MCRRs for these contracts using univariate $\operatorname{GARCH}(1,1)$ models for each contract (i.e. using the same model and procedure as used here in the full valuation approach). It would thus be concluded that the multivariate approach has been proved preferable in this instance, since, given that the required coverage has been achieved, the multivariate model has done so at a lower capital charge, which implies for the firm a smaller amount of capital tied up in a liquid form. However, both methodologies produce MCRRs that are on average slightly greater than were required for our chosen tests of model adequacy. This is shown by the results of the unconditional coverage test, also presented in Table 5, where none of the test statistics are significant, even at the $10 \%$ level. This suggests that the null hypothesis that the actual and nominal coverage rates are equal cannot be rejected, even for the univariate models which were excessively conservative. In fact, the percentage of exceedences would have had to have been as small as $1.2 \%$ or as big as $9.6 \%$, in order to be able to reject the null hypothesis at the 5\% level for a sample of this size, suggesting that the test is not very powerful.

Finally, Panels $\mathrm{C}$ and $\mathrm{D}$ of Table 5 present the conditional coverage tests for the null hypotheses of $\mathrm{H}_{0}: \mu=0.05$ and $\mathrm{H}_{0}: \lambda=0$ respectively in square brackets. The test statistics are all not significantly different from zero, indicating that correct conditional and unconditional coverage cannot be rejected for any of the models, either for the in-sample or the out-ofsample periods. 


\section{Conclusions}

This paper has investigated the possible use of multivariate GARCH models in calculating MCRRs for portfolios of assets. The model that we have applied here appears to have been relatively accurate, at least compared with equivalent calculations based on univariate models (see Brooks et al, 2000). Perhaps the most important result to be drawn from this paper is that more accurate MCRR estimates might be achievable if we can consider the VaR problem in a multivariate context, acknowledging explicitly that both variances and covariances may timevary. Given the importance of this technology and the consequences for the real economy if these models are not accurate, we hope that our results will make a valuable contribution to the debate about the VaR methodology. 


\section{References}

Berkowitz, J., 2000, How Accurate are the Value-at-Risk Models at Commercial Banks Working paper, Graduate School of Management, University of California at Irvine.

Bollerslev, T., 1986, Generalised Autoregressive Conditional Heteroscedasticity, Journal of Econometrics 31, 307-327.

Bollerslev, T., 1990, Modelling the Coherence in Short-Run Nominal Exchange Rates: A Multivariate Generalised ARCH Model, The Review of Economics and Statistics 72, 498505.

Bollerslev, T., Chou, R.Y., and Kroner, K.F., 1992 ARCH Modelling in Finance: A Review of the Theory and Empirical Evidence, Journal of Econometrics 52(5), 5-59.

Bollerslev, T., Engle, R. and Wooldridge, J.M., 1988, A Capital Asset Pricing Model with Time Varying Covariances, Journal of Political Economy 96, 116-131.

Brooks, C., Clare, A.D., and Persand, G., 2000, A Word of Caution on Calculating MarketBased Minimum Capital Risk Requirements. Journal of Banking and Finance 14(10), 1557 1574.

Brooks, C., and Persand, G., 2000, Value at Risk and Market Crashes Journal of Risk 2, 5-26

Christoffersen, P.F. 1998, Evaluating Interval Forecasts, International Economic Review 39, 841-862

Christoffersen, P.F. and Diebold, F.X., 2000, How Relevant is Volatility Forecasting for Financial Risk Management? Review of Economics and Statistics 82, 12-22

Clifford Chance, 1998, CADII moves forward, Newsletter: European Financial Markets, London.

Efron, B., 1982, The Jackknife, the Bootstrap, and Other Resampling Plans, Philadelphia, PA: Society for Industrial and Applied Mathematics.

Efron, B., and R. Tibshirani, 1993, An Introduction to the Bootstrap, Chapman Hall.

Engel, C. and Rodrigues, A.P., 1989, Tests of International CAPM with Time-Varying Covariances, Journal of Applied Econometrics 4, 119-138.

Engle, R.F., 2000 Dynamic Conditional Correlation - A Simple Class of Multivariate GARCH Models, Working paper, Stern School of Business, New York University

Engle, R.F. and Manganelli, S. 1999 CAViaR: Conditional Autoregressive Value at Risk by Regression Quantiles, University of California at San Diego working paper.

Hsieh, D.A., 1993, Implications of Nonlinear Dynamics for Financial Risk Management, Journal of Financial and Quantitative Analysis 28, 41-64. 
Johnson, N.L., 1949, Systems of Frequency Curves Generated by Methods of Translations, Biometrika, 149-175.

Ng, I., 1991, Test of the CAPM with Time-Varying Covariances: A Multivariate GARCH Approach, Journal of Finance 46, 1507-1522.

Schwert, G.W. and Seguin, P.J., 1990, Heteroscedasticity in Stock Returns, Journal of Finance XLV, 1129-1155. 
Table 1

Summary Statistics of Derivative Returns

\begin{tabular}{lcccc}
\hline Returns series & FTSE-100 & Long Gilt & Short Sterling & Portfolio \\
\hline Mean & 0.00034 & 0.00013 & 0.000042 & 0.00017 \\
Variance & $8.3 \mathrm{E}-05$ & $2.7 \mathrm{E}-05$ & $1.680 \mathrm{E}-06$ & $1.9068 \mathrm{E}-05$ \\
Skewness & $0.30^{* *}$ & $-0.091^{*}$ & $8.55^{* *}$ & $0.28^{* *}$ \\
Kurtosis & $2.7^{* *}$ & $3.4^{* *}$ & $199^{* *}$ & $3.5^{* *}$ \\
Normality $\dagger$ & $480^{* *}$ & $640^{* *}$ & $2223267^{* *}$ & $83^{* *}$ \\
$\mathbf{A C F}(\mathbf{1})$ & -0.0093 & -0.026 & -0.029 & -0.014 \\
$\mathbf{A C F}(\mathbf{2})$ & -0.011 & 0.00025 & -0.048 & -0.0035 \\
$\mathbf{A C F}(\mathbf{3})$ & -0.025 & 0.036 & $0.097 *$ & 0.011 \\
$\mathbf{A C F}(\mathbf{4})$ & 0.011 & -0.039 & -0.0044 & -0.023 \\
$\mathbf{A C F}(\mathbf{5})$ & -0.016 & 0.038 & 0.029 & 0.026 \\
$\mathbf{L B}-\mathbf{Q}(\mathbf{1 0})$ & 18.54 & 16.69 & 17.72 & 14.27 \\
\hline
\end{tabular}

Notes: $*$ and $* *$ represent significance at the $5 \%$ and $1 \%$ levels respectively; $\dagger$ Bera and Jarque test; $\mathrm{ACF}(j)$ denotes the autocorrelation coefficient at lag $j$; LB-Q(10) denotes the Ljung-Box Q statistic estimated using 10 lags, and which is asymptotically distributed as a $\chi^{2}(10)$ under the null hypothesis.

Table 2

Coefficient Estimates of GARCH(1,1) Model for the futures portfolio

\begin{tabular}{ccccc}
\hline \multicolumn{4}{c}{ Mean \& Variance Parameters } \\
\hline \multirow{3}{*}{ Portfolio } & $\mu$ & $\gamma$ & $\alpha$ & $\beta$ \\
& $1.2 \mathrm{E}-05$ & $0.093^{* *}$ & $9.6 \mathrm{E}-02^{* *}$ & $0.86^{* *}$ \\
& $(1.1 \mathrm{E}-04)$ & $(0.0038)$ & $(8.7 \mathrm{E}-08)$ & $(0.0037)$ \\
\hline
\end{tabular}

Notes: Standard errors are in parentheses; $* *$ indicates significance at the $1 \%$ level.

Table 3

Correlation Coefficients

\begin{tabular}{lccc}
\hline \multicolumn{1}{c}{ Contracts } & FTSE-100 Index & Long Gilt & Short Sterling \\
\hline & & Correlation Coefficients & \\
FTSE-100 Index & - & - & - \\
Long Gilt & 0.51 & - & - \\
Short Sterling & 0.33 & 0.34 & - \\
\hline
\end{tabular}


Table 4

Coefficient Estimates of MGARCH(1,1) Model with time-varying correlation

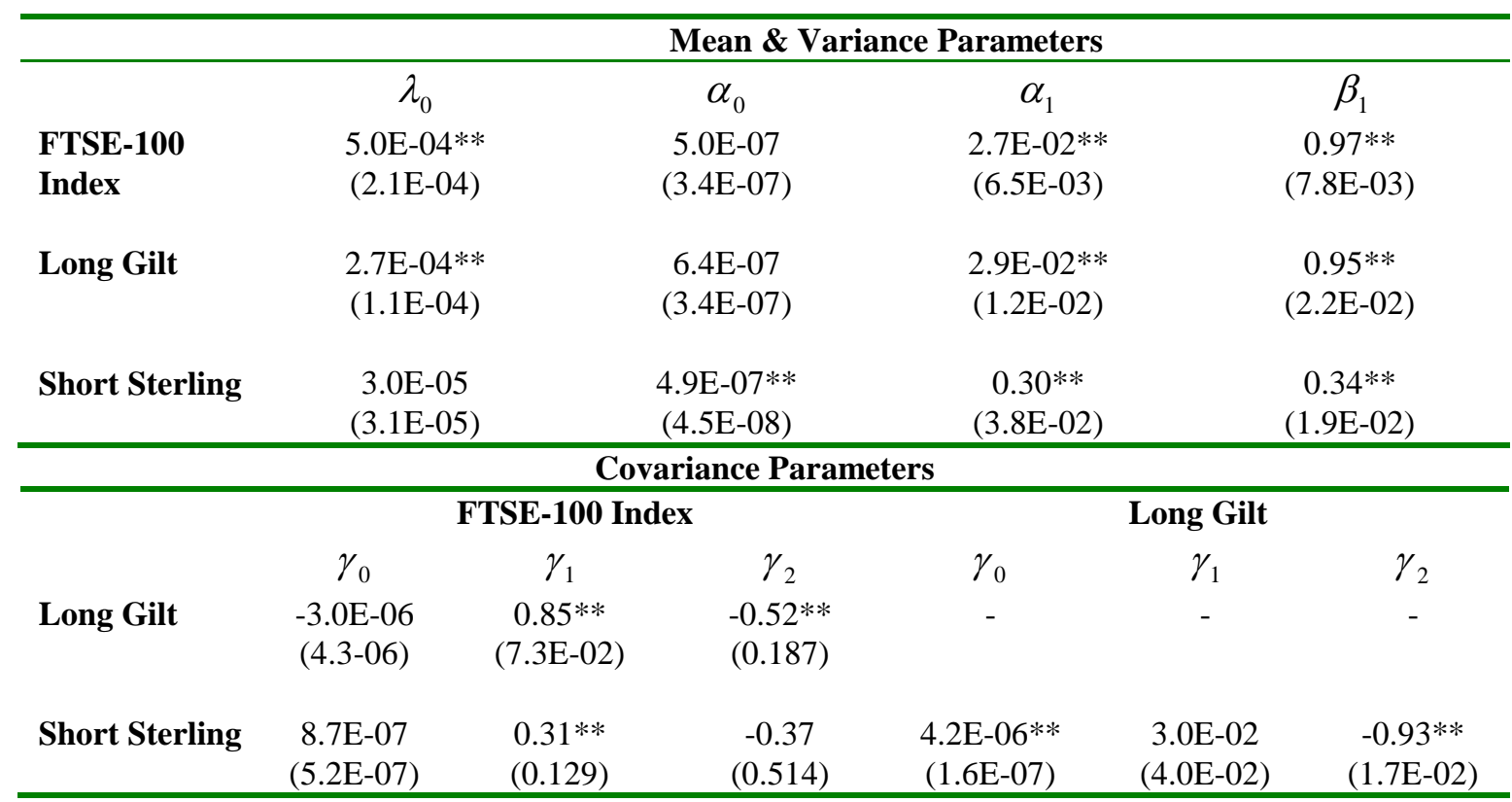

Notes: For model description - see text. Standard errors are in parentheses. $* *$ indicates significance at the $1 \%$ level. 


\section{Table 5}

\section{Panel A:}

MCRRs for $95 \%$ coverage probability as a percentage of the initial value for equally weighted portfolios.

\begin{tabular}{lcc}
\hline & Long Positions & Short Positions \\
\hline & Full Valuation Univariate GARCH & 1.54 \\
\hline $\mathbf{1}$ day & 1.48 & 3.74 \\
$\mathbf{1}$ week & 3.52 & 9.16 \\
$\mathbf{1}$ month & 8.98 & 18.74 \\
\hline 3 months & 14.13 & 1.15 \\
\hline $\mathbf{1}$ day & MGARCH Model & 3.24 \\
$\mathbf{1}$ week & 1.06 & 8.43 \\
$\mathbf{1}$ month & 3.06 & 16.94 \\
\hline
\end{tabular}

Panel B:

Confidence intervals for the MCRRs

\begin{tabular}{lcc}
\hline & Long Positions & Short Positions \\
\hline & Full Valuation Univariate GARCH & \\
\hline $\mathbf{1}$ day & {$[1.37,1.55]$} & {$[1.45,1.65]$} \\
$\mathbf{1}$ week & {$[3.28,3.70]$} & {$[3.52,4.00]$} \\
$\mathbf{1}$ month & {$[8.35,9.42]$} & {$[8.61,9.80]$} \\
$\mathbf{3}$ months & {$[13.14,14.84]$} & {$[17.62,20.06]$} \\
\hline $\mathbf{1}$ day & MGARCH Model & {$[1.13,1.20]$} \\
$\mathbf{1}$ week & {$[1.04,1.10]$} & {$[3.17,3.37]$} \\
$\mathbf{1}$ month & {$[3.00,3.18]$} & {$[8.26,8.76]$} \\
3 months & {$[7.30,7.74]$} & {$[16.60,17.61]$} \\
\hline
\end{tabular}

\section{Panel C:}

Model adequacy: in-sample tests

\begin{tabular}{lcc}
\hline & Long Positions & Short Positions \\
\hline Full Valuation Univariate GARCH & $4.8 \%(0.01)[0.43,0.76]$ & $3.2 \%(0.84)[0.34,0.99]$ \\
MGARCH Model & $4.8 \%(0.01)[0.15,0.66]$ & $4.8 \%(0.01)[0.23,0.68]$ \\
\hline
\end{tabular}

Panel D:

Model adequacy: out-of-sample tests

\begin{tabular}{lcc}
\hline & Long Positions & Short Positions \\
\hline Full Valuation Univariate GARCH & $4.0 \%(0.24)[0.94,0.89]$ & $4.0 \%(0.24)[0.83,0.72]$ \\
MGARCH Model & $4.8 \%(0.01)[0.24,0.98]$ & $4.4 \%(0.09)[0.30,1.04]$ \\
\hline
\end{tabular}

Note: Unconditional coverage test statistics are given in parentheses (.) in Panels $\mathrm{C}$ and $\mathrm{D}$, and conditional coverage test statistics are given in square brackets [.,.] for $\mu$ and $\lambda$ respectively. The unconditional coverage statistics are asymptotically distributed as $\chi^{2}(1)$ variates under the null hypothesis that the actual and nominal coverage rates are equal. The conditional coverage statistics ar asymptotically distributed as a $t_{248}$ under the null hypotheses. 
Figure 1: FTSE Index Returns September 1991 - September 1996

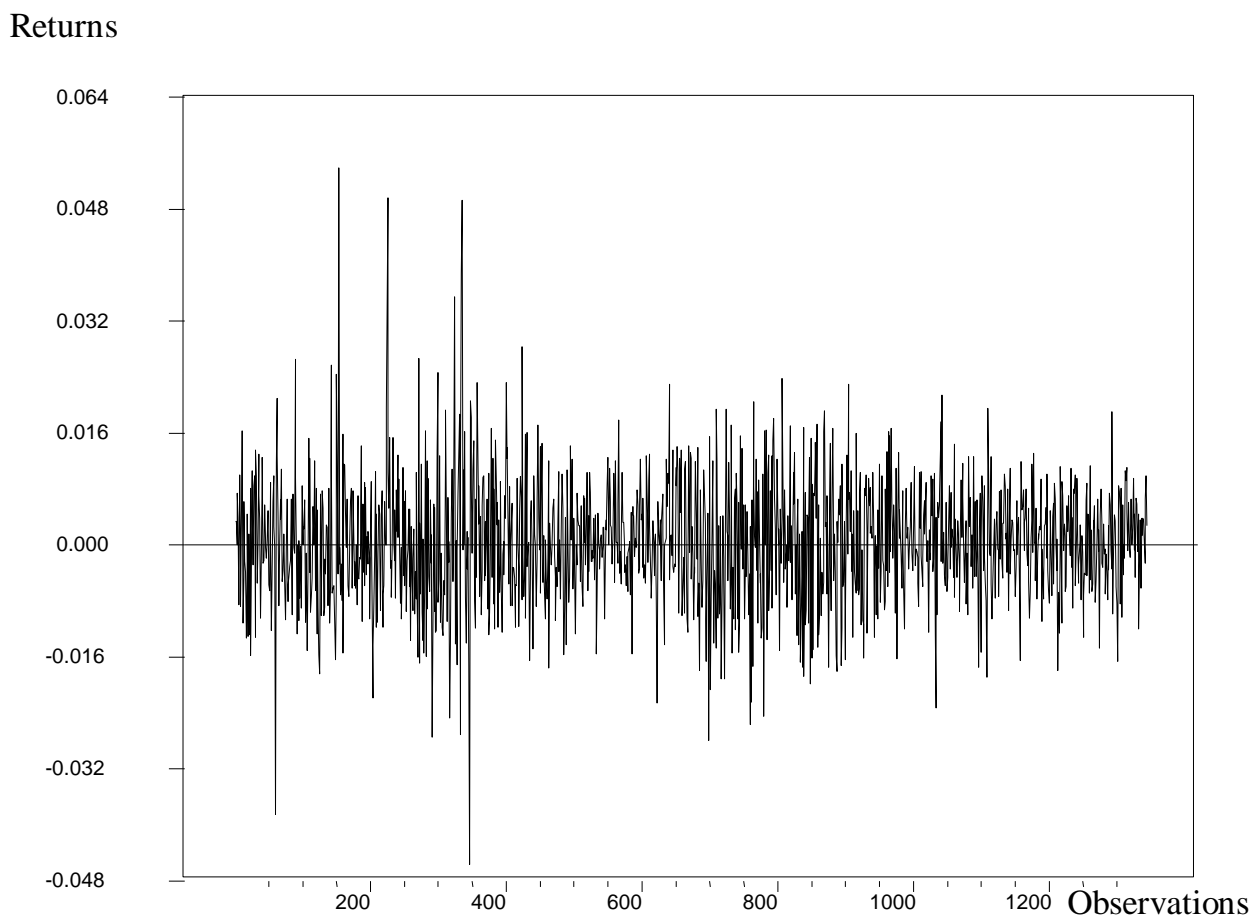

Figure 2: Long Gilt Index Returns September 1991 - September 1996

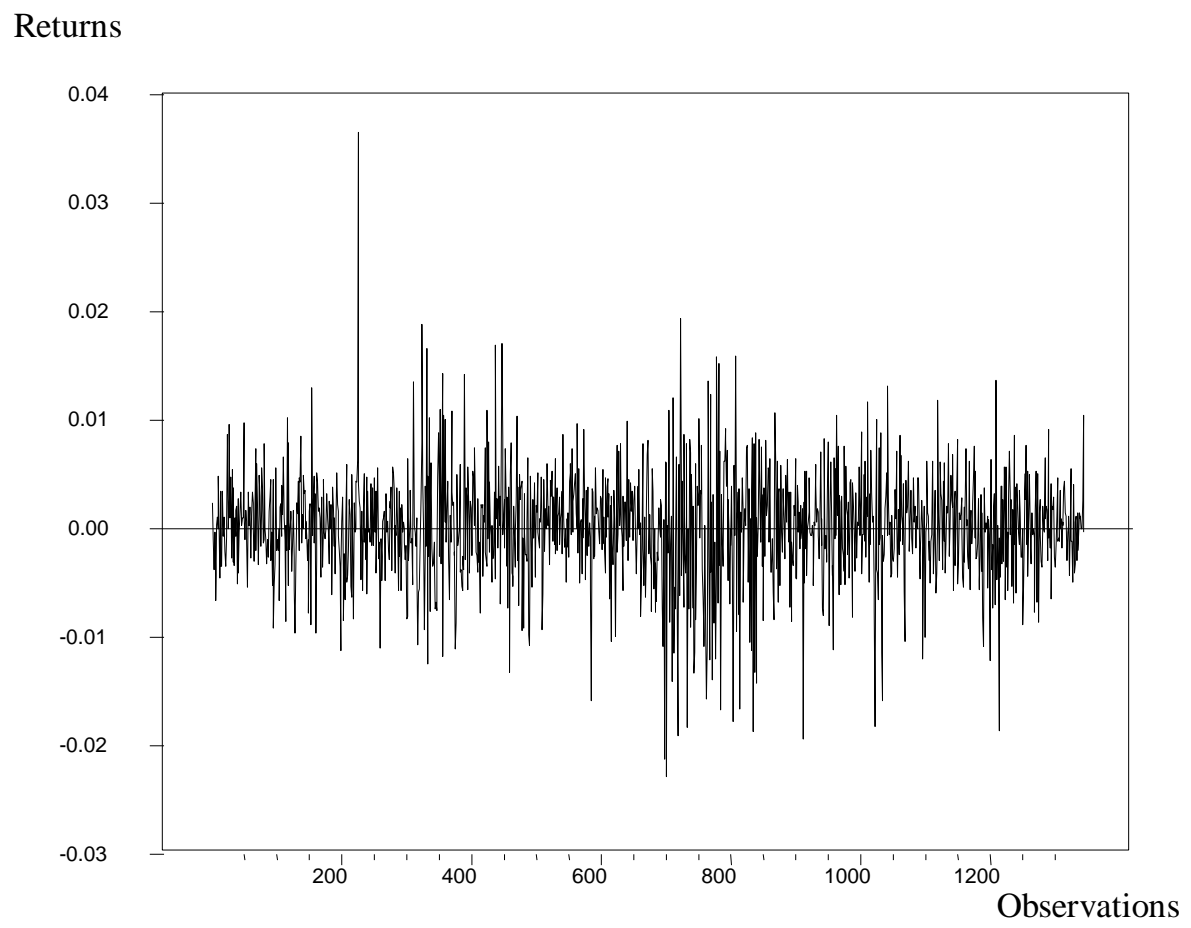


Figure 3: Short Sterling Index Returns September 1991 - September 1996 Returns

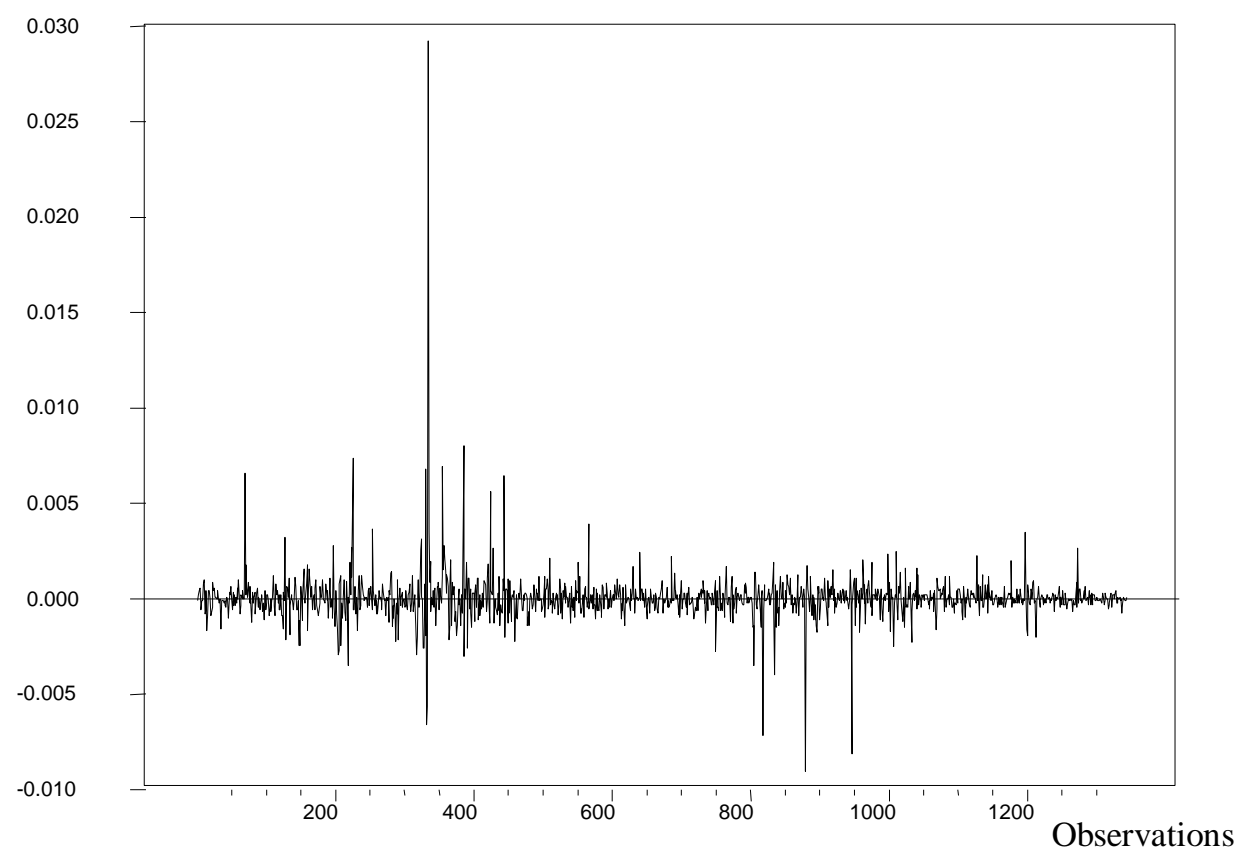

Figure 4: Time varying Covariance between the LIFFE FTSE-100 and Long gilt contracts $\left(h_{12}\right)$

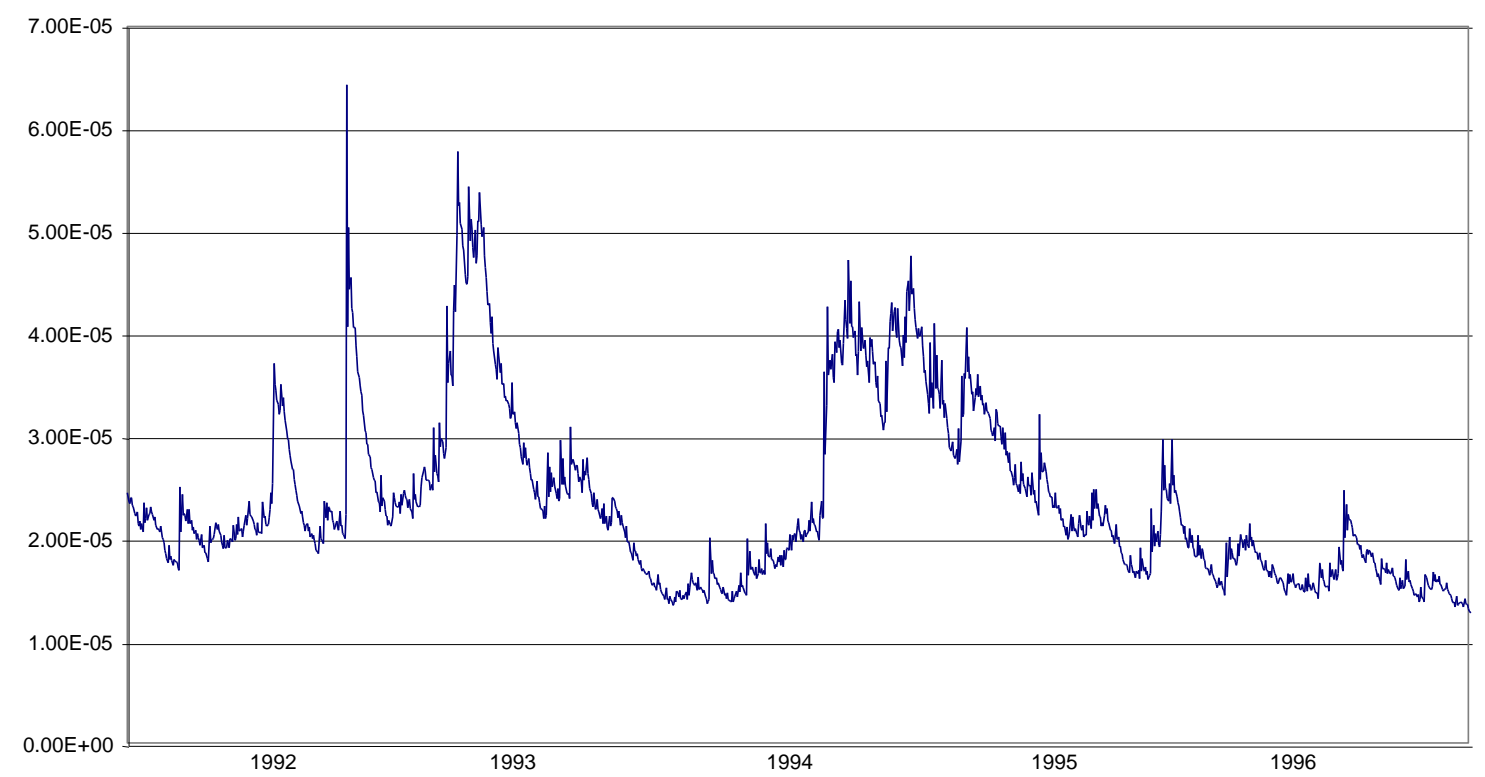

